EDITORIAL

\title{
A Educação, a pandemia e a sociedade do cansaço
}

Érika Dias

Han, em seu livro "A Sociedade do Cansaço", fez um retrato do mundo de antes da pandemia da Covid-19 demonstrando que vivemos numa época de velocidade e de esgotamento, na qual o sistema de poder vigente valoriza indivíduos inquietos, hiperativos, que se arrastam no cotidiano produtivo, quase sempre bem-sucedidos e que executam inúmeras e variadas tarefas. Estamos vivendo na sociedade do desempenho, constituída por uma nova subjetividade proveniente das transformações sócio-históricas ocorridas desde o final do século XX (HAN, 2017).

Foucault, ainda antes de Han, seguia na mesma linha de pensamento ao declarar que, não no final do século XX, mas desde meados do século XVIII, vivemos em um sistema de biopoder ou biopolítica, um sistema que busca otimizar um estado de vida na população, a fim de criar indivíduos economicamente ativos. Produzir, inovar, responder com criatividade às situações de trabalho, de estudo, de relacionamento são o que se espera de todos nós. Autossuperação, iniciativa, eficiência e flexibilidade explicam a sociedade do desempenho de Han (2017) e a biopolítica de Foucault (2012).

Foucault (2012) e Han (2017) têm em comum a ideia de que, nessa sociedade do desempenho, na qual impera a biopolítica, impera também o cansaço e predomina a autoexploração. $\mathrm{O}$ indivíduo do século XXI quer sempre produzir mais e melhor porque é essa resposta de autossuperação, desempenho, inovação que se espera dele. E a pandemia, ao que parece, acelerou tudo isso. Hoje, neste novo normal, podemos entender o vírus como espelho da sociedade descrita por Han (2017) como sendo a "sociedade do cansaço".

O coronavírus é um espelho que reflete e agrava as crises da nossa sociedade, os sintomas das doenças que sofríamos antes da pandemia - depressão, ansiedade, problemas de sono - se destacam com mais força, e um desses sintomas é o cansaço (BARROS et al., 2020). Os contagiados padecem de extremo abatimento

a Fundação Cesgranrio, Rio de Janeiro, RJ, Brasil/ Universidade Nova de Lisboa, Lisboa, Portugal. 
e esgotamento; para os curados, uma das sequelas é justamente a síndrome da fadiga, que vai além do simples cansaço. Os saudáveis em home office se cansam mais do que quando trabalham presencialmente, já que é um trabalho que carece de rituais e de estruturas temporárias fixas. É esgotante trabalhar sozinho, na frente da tela do computador, e a falta de contatos sociais é exaustiva. Tudo isso gera um impacto, porque todas as pandemias são geradoras de forte impacto social, econômico e político.

Desde março de 2020 estamos construindo respostas para o novo mundo que surgiu com a pandemia. Novo mundo, novo normal, novas vacinas, teletrabalho, ensino remoto, novas formas de nos relacionarmos, com distanciamento, máscaras, tudo isso foram adaptações que tivemos de fazer para manter o desempenho e os resultados que são esperados de nós, seja no campo familiar, no profissional, no educacional ou na vida em sociedade. Nessa nossa nova realidade, as famílias estão em casa - trabalhando e estudando -, tentando permanecer sãs física e mentalmente. Algo bastante complexo, pois a ansiedade, a depressão e o estresse, que já eram sintomas da sociedade do século XXI, aumentaram durante a pandemia (DIAS; PINTO, 2020).

A pandemia, num primeiro momento, desacelerou todos nós, parou o mundo, criando uma nova realidade. Todos os setores da sociedade sofreram impactos brutais, com restrições de circulação e de atividades, mudanças nos hábitos de higiene, ao mesmo tempo em que nos fez conviver com a possibilidade da infecção e com a fatalidade de milhões de pessoas. Num segundo momento, exigiu (e exige) reação, da população, dos sistemas de saúde, dos cientistas, dos governantes -, que nem sempre corresponderam com eficiência ou idoneidade, negando a ciência, contribuindo para o aumento do número de mortos -, das organizações de saúde e humanitárias e das instituições ligadas à Educação.

No que se refere à Educação, a crise causada pela Covid-19, em 2020, levou ao encerramento das aulas em escolas e em universidades, o que afetou mais de $90 \%$ dos estudantes do mundo, segundo a Organização das Nações Unidas para a Educação, a Ciência e a Cultura (UNESCO, 2020).

Conforme a Unesco, um ano após o início da pandemia em 2020, quase metade dos estudantes do mundo ainda se sentem afetados pelo fechamento parcial ou total das escolas, e mais de 100 milhões de crianças adicionais cairão abaixo do nível mínimo de proficiência em leitura como resultado dessa crise de saúde. Priorizar a recuperação da Educação é primordial para evitar uma catástrofe que afetará todo uma geração. Governos e instituições estão apoiando milhares de crianças em seus esforços para mitigar o impacto do fechamento de escolas, 
para lidar com as perdas de aprendizagem e adaptar os sistemas de Educação, especialmente em comunidades vulneráveis e desfavorecidas, porque reconhecem que existem desigualdades sociais (UNESCO 2021).

Em texto recente, intitulado "Ainda tempos estranhos", Nogueira afirma que "a Educação ocorre num contexto cultural e social, e não num vazio social abstrato" (2021, p. 312). E vai além, exorta para a necessidade de se atentar para as variáveis que intervêm nesse processo, indicando a desigualdade como um dos grandes problemas que a pandemia desvelou. $\mathrm{O}$ ensino remoto nos fez ver a diferença profunda de acesso dos alunos a recursos tecnológicos e educacionais. Ora, sabemos que há desigualdades no sistema de ensino público e privado, o que os governos, as instituições e a sociedade precisam fazer é responder ao problema, de forma que se possa superá-lo.

Um exemplo prático diz respeito à aprendizagem. Sabemos que o não cumprimento do ano letivo com todos os elementos que o constituem levou a um déficit de aprendizagem, em escolas públicas e particulares, e esse é sem dúvidas um dos grandes problemas que enfrentaremos, mas precisamos pensar para além disso. Num mundo pós-pandemia, será preciso elaborar projetos e leis para apoiar educadores, estudantes e famílias, priorizando os menos privilegiados (BRASIL, 2020), implementando novamente, em pleno século XXI, os ideais do Iluminismo: a defesa do direito à Educação de qualidade para todas as pessoas.

Será preciso avançar para além do ensino remoto e do aumento da carga horária, será necessário criar condições para ajudar os alunos mais prejudicados. A escola precisará fazer um diagnóstico dos alunos como base para a retomada dos programas de ensino presencial ou híbrido. E, a partir disso, fazer intervenções que incluam, do lado pedagógico, o ensino estruturado nos conteúdos que não foram apreendidos, o uso estratégico dos deveres de casa e de programas de leitura e, para os alunos com mais dificuldade, programas intensivos de tutoria em pequenos grupos (VIEIRA; SILVA, 2020). E os governos, por meio das políticas públicas, precisarão encaminhar esses projetos.

Refletindo sobre o que nos espera num mundo pós-pandemia, o número 112 da Ensaio reúne, mais uma vez, uma gama de artigos que discutem temas e objetos de estudo do campo educacional de grande relevância no contexto da realidade atual. Educação e pandemia, aprendizagem na Educação Básica, avaliação, políticas públicas, inclusão, são temas dos artigos ora publicados, objetivando ampliar o debate e as reflexões sobre assuntos atuais e que importam a todos. 
Os artigos abordam questões que têm sua gênese nas inquietações motivadas pela pandemia, bem como questionam e refletem sobre programas de avaliação da graduação e da pós-graduação no Brasil, analisam as trajetórias de estudantes portugueses e brasileiros no Ensino Superior, discutem o equilíbrio entre trabalho e vida, a fim de entender o impacto do trabalho no bem-estar dos professores, procuram entender porque está ocorrendo o ingresso de pessoas cada vez mais jovens (entre 15 e 17 anos) na Educação de Adultos, ou ainda como se dá o processo de inclusão educacional de estudantes universitários com deficiência no Ensino Superior público em Honduras. Esses são alguns dos temas aqui publicados que demonstram a amplitude e a complexidade da área da Educação.

Abrimos o debate com o artigo dos professores e pesquisadores do Instituto dos Estudos Superiores de Fafe, em Portugal, Cândido Alberto Gomes, Susana Oliveira e Sá, Enrique Vázquez-Justo, Cristina Costa-Lobo, intitulado "Education during and after the pandemics", no qual analisam o tratamento improvisado que a Educação recebeu durante a pandemia e os planejamentos necessários do que é preciso fazer no período pós-pandêmico. Os autores realçam as crises dentro da crise da saúde gerada pela Covid-19, tais como a pobreza e a violência, e entendem que é preciso apoiar famílias, estudantes e educadores, a fim de colmatar as consequências no pós-pandemia, concluindo que a preservação de recursos mínimos para a Educação é ponto de honra para os laços histórico-sociais e para o soerguimento das economias.

Do Mato Grosso do Sul, temos o artigo "A produção intelectual sobre o Qualis Periódicos na área de Educação: um diálogo com as pesquisas acadêmicas (2008-2018)", no qual as autoras, Eliane Souza de Carvalho e Giselle Cristina Martins Real, tecem um panorama do Programa Qualis, analisando criticamente o programa e as mudanças que vêm ocorrendo nos últimos quadriênios, inclusive a recente proposta da comissão de acompanhamento do Plano Nacional de Pós-Graduação - PNPG 2011-2020 - de extinguir o Programa Qualis, apontando que tal ruptura irá incidir diretamente na gestão dos periódicos e nos programas de pós-graduação.

Dos pesquisadores da Fundação Cesgranrio, Kaizô Iwakami Beltrão, Mônica Mandarino, Ricardo Servare Megahós e Mônica Guerra Ferreira Pedrosa, temos o artigo "Effects of socioeconomic status on the use of written language: does it extend into Brazilian Higher Education?". Nele, os autores, a partir dos pressupostos de Bourdieu e Passeron - que defendiam a tese de que a escola era o principal locus para legitimar e perpetuar as diferenças de classe - analisaram as notas de desempenho linguístico (português), a fim de demonstrar se os grupos socioeconômicos mais afluentes apresentaram maior proficiência no componente linguístico do Exame Nacional de Desempenho de Estudantes (Enade). 
Do Sul, temos o artigo "Avaliação do nível de satisfação discente de uma instituição de Ensino Superior: uma análise dos métodos da Teoria Clássica da Medida e da Teoria da Resposta ao Item", no qual os pesquisadores Anna Cecilia Amaral Petrassi, Antonio Cezar Bornia e Dalton Francisco Andrade compararam as informações geradas pelo processo de autoavaliação de uma Instituição Federal de Educação Superior, no contexto do Sistema Nacional de Avaliação da Educação Superior, com as mesmas informações tratadas a partir do uso da Teoria da Resposta ao Item (TRI) no lugar da Teoria Clássica da Medida, com o objetivo de demonstrar como o processo de avaliação pode se favorecer com a utilização da TRI.

A seguir, temos o artigo "Percursos de estudantes da Educação Superior com trajetórias de insucesso", no qual professoras de instituições do Brasil e de Portugal - Lourdes Maria Bragagnolo Frison (in memorian), Ana Margarida Veiga Simão, Paula da Costa Ferreira e Paula Paulino -, analisaram as trajetórias de insucesso e identificaram motivos, estratégias e expectativas de estudantes portugueses e brasileiros que elaboraram uma narrativa de autoformação. O estudo demonstra motivos do insucesso - desmotivação, ansiedade, contexto familiar, entre outros - e como os estudantes utilizam a motivação e as estratégias autorregulatórias para obterem sucesso.

Em seguida, temos o artigo "Work-life balance in higher education: a systematic review of the impact on the well-being of teachers", uma contribuição de pesquisadores e de professores da Universidade Tecnológica do Paraná, Luciane Silva Franco, Claudia Tania Picinin, Luiz Alberto Pilatti e Antônio Carlos Franco. Nele, discutem o equilíbrio entre o trabalho e a vida no Ensino Superior e seu impacto no bem-estar dos professores. Os resultados da análise apontaram estratégias para melhorar o equilíbrio entre vida profissional e pessoal, como, por exemplo, implementar políticas voltadas para os professores, objetivando melhorar o clima organizacional, reduzir a desigualdade de gênero na graduação e na pós-graduação e organizar seminários sobre saúde, bem-estar, gestão do tempo e relacionamento.

Da Universidade do Estado da Bahia, temos o artigo "Juvenilização da EJA e as implicações no processo de escolarização", no qual os autores, Alcides Alves de Souza Filho, Atenuza Pires Cassol e Antônio Amorim discutiram o fenômeno da juvenilização que ameaça a caracterização da Educação de Jovens e Adultos (EJA) com a presença de alunos cada vez mais jovens, excluídos do ensino regular, que acabam causando conflitos intergeracionais, afetando as relações na sala de aula, preocupando professores e gestores das escolas. Ao mesmo tempo que entenderam que precisavam incluir esses jovens no programa, a fim de participarem do processo de escolarização. 
No campo dos estudos sobre inclusão, temos um artigo do professor Eddy PazMaldonado, da Universidad Nacional Autónoma de Honduras, intitulado "La inclusión educativa del estudiantado universitario en situación de discapacidad en Honduras", no qual discute a realidade dos estudantes universitários com deficiência no Ensino Superior. O estudo demostra que o progresso foi lento e os desafios para estabelecer universidades mais inclusivas ainda são grandes. Ainda há uma forte convicção de que esses alunos são limitados no meio ambiente acadêmico, devido à sua condição e não devido às barreiras que ainda existem. Isso revela o desconhecimento e a pouca importância que o assunto ainda tem em todo o país.

Dos pesquisadores da Universidade Federal de São Paulo, Bruna de Oliveira Julião, Carolina Toledo Piza e Claudia Berlim de Mello, temos o artigo "Escala de sondagem do desenvolvimento neuropsicomotor e de habilidades acadêmicas para o Ensino Fundamental I: percepção de professores". O estudo analisou aspectos da aplicação e adequação da Sondagem do Desenvolvimento do Aluno (SDA), um instrumento para monitoramento contínuo de aspectos do desempenho acadêmico e do neurodesenvolvimento dos alunos dos primeiros anos do Ensino Fundamental, na perspectiva dos professores. As autoras apontam que aspectos do neurodesenvolvimento são pouco contemplados nas avaliações dos alunos, ao contrário das aquisições de habilidades relacionadas à leitura, à escrita e à matemática. As pesquisadoras entendem que, mais do que oferecer materiais e instrumentos, é preciso aprofundar a reflexão junto aos professores sobre como utilizá-los e conscientizá-los sobre a importância deles.

Fabiana A. Filipe, Dayane dos Santos Silva e Áurea de Carvalho Costa, da Universidade Estadual Paulista "Júlio de Mesquita Filho", apresentam o artigo "Uma base comum na escola: análise do projeto educativo da Base Nacional Comum Curricular", no qual analisaram o projeto educativo proposto como fundamento da Base Nacional Comum Curricular (BNCC). No estudo, as autoras identificaram que a BNCC se fundamenta num projeto educativo de formação para a empregabilidade, com a centralidade das competências, a partir de um modelo de ensino direcionado, distanciando-se de um projeto educativo que visasse a uma formação crítica e emancipatória.

Em seguida, José Leudo Maia e Marcos Antônio Martins Lima apresentam o artigo intitulado "Modelagem de Equações estruturais e os testes de seleção - caso do vestibular da Universidade Estadual do Ceará - Uece". O estudo analisou o uso da modelagem de equações estruturais para avaliar a qualidade do modelo empregado pela universidade no processo de seleção de seus vestibulandos. Os resultados demonstraram que o modelo é robusto e consistente, permitindo uma 
boa discriminação entre as notas dos vestibulandos, principalmente aqueles com o mesmo número de questões respondidas corretamente.

E, por último, na seção Página Aberta, temos o artigo "Avaliação do processo de formação do caráter em crianças na Educação Infantill”, de Bruna Rodrigues Cardoso Miranda e Maria Judith Sucupira da Costa Lins, da Universidade Federal do Rio de Janeiro, no qual as autoras tratam da possibilidade de avaliação do início do processo de formação do caráter de crianças na Educação Infantil. A abordagem metodológica foi a pesquisa-ação, por meio de observação, intervenções, oficinas e questionários. Atividades especialmente criadas para essa pesquisa foram selecionadas e apresentadas às crianças. Resultados mostram que é possível avaliar a evolução da aprendizagem e a prática de virtudes nas crianças.

Em conformidade com o conceito de sociedade do desempenho defendido por Han (2017), esse conjunto de trabalhos demonstra que a pesquisa não parou, nem a disseminação dos estudos cessou nesses "tempos ainda estranhos". O processo até foi se acelerando. Nesse número, tão diverso, o leitor poderá constatar que o Ensino Superior, a Educação Infantil e o Ensino Fundamental constituíram-se como os fios condutores, entrelaçando realidades nacionais e internacionais, trazendo à vista questões que são relevantes para a Educação em todo o mundo.

A Ensaio deseja uma boa leitura a todos e renova o compromisso de continuar a promover a reflexão, o debate e a difusão de estudos que contribuam para o avanço do conhecimento na área da Educação. 


\section{Referências}

BARROS, M. B. A. et al. Relato de tristeza/depressão, nervosismo/ansiedade e problemas de sono na população adulta brasileira durante a pandemia de Covid-19. Epidemiologia e Serviços de Saúde, Brasília, DF, v. 29, n. 4, e2020427, set. 2020. http://dx.doi.org/10.1590/s1679-49742020000400018

BRASIL. Ministério da Educação. Conselho Nacional da Educação. Resolução $\mathrm{CNE} / \mathrm{CP}^{\circ}$ 2, de 10 de dezembro de 2020. Institui Diretrizes Nacionais orientadoras para a implementação dos dispositivos da Lei n ${ }^{\circ} 14.040$, de 18 de agosto de 2020, que estabelece normas educacionais excepcionais a serem adotadas pelos sistemas de ensino, instituições e redes escolares, públicas, privadas, comunitárias e confessionais, durante o estado de calamidade reconhecido pelo Decreto Legislativo $\mathrm{n}^{\mathrm{o}}$ 6, de 20 de março de 2020. Diário Oficial da União, Brasília, DF, 11 dez. 2020.

DIAS, E.; PINTO, F. C. F. A Educação e a Covid-19. Ensaio: Avaliação e Políticas Públicas em Educação, v. 28, n. 108, p. 545-554, jul./set. 2020. https://doi.org/10.1590/S0104-40362019002801080001

FOUCAULT, M. Nascimento da biopolítica. São Paulo: Martins Fontes, 2012.

HAN, B.-C. Sociedade do cansaço. Petrópolis: Vozes, 2017.

MAIA, B. R.; DIAS, P. C. Ansiedade, depressão e estresse em estudantes universitários: o impacto da Covid-19. Estudos de Psicologia, Campinas, v. 37, e200067, 2020. https://doi.org/10.1590/1982-0275202037e200067

NOGUEIRA, S. M. A. Ainda tempos estranhos. Ensaio: Avaliação e Políticas Públicas em Educação, v. 29, n. 111, p. 311-317, abr./jun. 2021. https://doi. org/10.1590/S0104-4036202100029011100001

UNESCO. A Comissão Futuros da Educação da Unesco apela ao planejamento antecipado contra o aumento das desigualdades após a Covid-19. Paris: Unesco, 2020. Disponível em: https://pt.unesco.org/news/comissao-futuros-da-educacao-daunesco-apela-ao-planejamento-antecipado-o-aumento-das Acesso em: 4 jun. 2020.

UNESCO. Educação: da interrupção à recuperação. Paris: Unesco, 2021. Disponível em: https://pt.unesco.org/covid19/educationresponse. Acesso em: 11 jun. 2021.

VIEIRA, M. F.; SILVA, C. M. S. A Educação no contexto da pandemia de Covid-19: uma revisão sistemática de literatura. Revista Brasileira de Informática na Educação - RBIE, Porto Alegre, v. 28, p. 1013-1031, 2020. https://doi.org/10.5753/rbie.2020.28.0.1013 


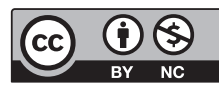

\section{Informações sobre a autora}

Érika Dias: Doutora em História Moderna pela Universidade Nova de Lisboa. Editora da revista Ensaio: avaliação e políticas públicas em Educação. Pesquisadora correspondente do Centro de Humanidades da Universidade Nova de Lisboa. Contato: erikadias@, cesgranrio.org.br

(iD) http://orcid.org/0000-0002-5608-646X 